Journal of Applied Pharmaceutical Science Vol. 7 (07), pp. 070-076, July, 2017

Available online at http://www.japsonline.com

DOI: $10.7324 / J A P S .2017 .70712$

ISSN 2231-3354 (cc)) BY-NC-SA

\title{
Evaluation of Plant Food Extracts in Experimental Model of Alzheimer's Like Disease Induced by Aluminum Lactate in Rats
}

\author{
Sahar Y. Al-Okbi ${ }^{1}$, Doha A. Mohamed ${ }^{1}$, Mohamed Abdel Fatah ${ }^{2}$, Kholoud Abdel Aal ${ }^{2}$, Shaimaa E Mohammed ${ }^{1}$ \\ ${ }^{1}$ Nutrition and Food Sciences Department, National Research Centre, El Buhouth Street, 12622, Dokki, Cairo, Egypt. \\ ${ }^{2}$ Biochemistry Department, Faculty of Science, Ain Shams University, Cairo, Egypt.
}

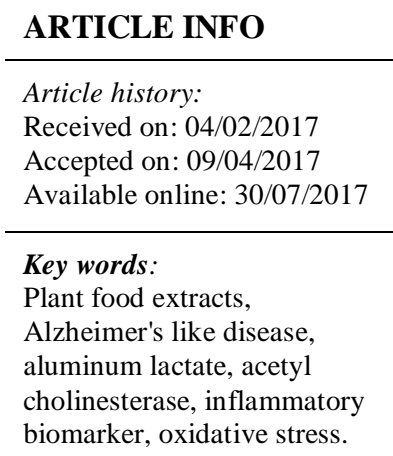

\begin{abstract}
In the present research, the beneficial effect of plant food extracts in Alzheimer's like model, induced by aluminum, was studied in rats. A healthy control group without any treatments and a control with induced Alzheimer's like disease (ALD) were run. Tests groups of rats were treated with daily oral doses of methanol extract of Carica papaya leaves and fruits, Vitis venifera leaves and fruits, Origanum majorana herb, and petroleum ether extract of Carica papaya seeds separately for 5 weeks. Rats of test groups and control ALD received daily intraperitoneal injection of aluminum lactate starting from the $2^{\text {nd }}$ week. Plasma and brain tissues were biochemically analyzed. Control rats with ALD demonstrated a significant increase in erythrocyte sedimentation rate, plasma malondialdehyde, nitrite, tumor necrosis factor - alpha and cholinesterase activity with significant reduction in plasma vitamin $\mathrm{C}$ and $\mathrm{E}$ compared to control healthy rats. Brain malondialdehyde and acetyl cholinesterase activity showed significant elevation in control rats with ALD. The studied plant extracts showed efficient inhibition of oxidative stress, inflammation, and cholinesterase activity in plasma and brain with variable degrees. Both brain oxidative stress and acetyl cholinesterase activity were reduced by methanol extracts of Vitis venifera and Carica papya fruits.
\end{abstract}

\section{INTRODUCTION}

Aluminium (Al) is widely used in industry such as in manufacturing cooking utensils and pharmaceuticals like antacids and antiperspirants thereby reach the human systemic circulation. Also, workers in such $\mathrm{Al}$ industries and others are daily exposed to such metal through inhalation and or skin contact. Al possesses toxic effect specially neurotoxicity. It is accused in the development of neurodegenerative diseases including Alzheimer's disease (AD) which is perpetuated to elevation of oxidative stress, inflammation, apoptosis, and induction of neurofibrillary tangles in the brain and gene expression (Maya et al., 2016).

\footnotetext{
* Corresponding Author
}

Sahar Y. Al-Okbi, Affiliation: Nutrition and Food Sciences Department, National Research Centre, Address: El Buhouth Street, 12622, Dokki,

Cairo, Egypt.Tel:00201003785152,e-mail: S_Y_alokbi@ hotmail.com
There are many arguments concerning the cause and mechanism of action of AD however evidence supports the involvement of metals like magnesium and aluminium in the pathogenesis of the disease. Dementia is the main feature of AD patients; the disease is characterized by the presence of $\beta$-amyloid protein (A $\beta$ ) and tau hyperphosphorylation which are influenced by changes in the homeostasis of the above mentioned metals (Wang and Wang, 2016). Natural bioactive agents could have beneficial effects towards $\mathrm{AD}$, from which nutraceuticals are worthy to be investigated in this concern. Nutraceuticals are concentrated form from bioactive compounds prepared from plants food that could protect or treat one or more chronic disease. We hypothesized that nutraceuticals possess antioxidant, anti-inflammatory and acetyl cholinesterase (AChE) inhibitory activity could reduce the progression or delay the onset of AD. This is because AD patients were reported to suffer from high oxidative stress, inflammation and high activity of AChE that have direct link to memory deficit (Law et al., 2001; Saez-Valero et al., 2002). 
Also high oxidative stress plays a major role in the formation of amyloid plaques and neurofibrillary tangles present in the brain of AD patients (yao et al., 1999). In a previous work belongs to the present research team different plants food methanol and petroleum ether extracts were assayed for their invitro antioxidant, in-vivo anti-inflammatory in rat model of acute inflammation and ex-vivo acetyl cholinesterase inhibitory activity (Abdel Fatah et al., 2009). From that study; methanol extract of Carica papaya leaves and fruits, grape leaves and fruits and Origanum majorana herb, and petroleum ether extract of Carica papaya seeds that showed promising activity were selected to be evaluated in the present study in experimental model of Alzheimer's like disease (ALD) induced by Al lactate in rats. So the objective of the present study was to find out a better way to prevent the progression in neurodegenerative diseases specially $\mathrm{AD}$ induced by $\mathrm{Al}$ through natural remedies represented by nutraceuticals.

\section{MATERIALS AND METHODS}

\section{I-Materials \\ Plants}

The plants used in the present study were the ripe fruits, leaves and seeds of Carica papaya L. family Caricaceae (papaya), herbs of Origanum majorana L. family Lamiaceae (marjoram), ripe fruits (seedless) and leaves of Vitis vinifera L. family Vitaceae (grape). All plant materials were purchased from local market except for Carica which was obtained from Ministry of Agriculture, Egypt. The plants were authenticated by Dr. Tereez Labib, Consultant of Plant Taxonomy, Ministry of Agriculture, Giza, Egypt.

\section{Chemicals}

Aluminum lactate was obtained from Riedel-de Haën, Germany for induction of Alzheimer-like disease in rats.

\section{Animals}

Male albino rats of body weight ranged from 185 to 205 $\mathrm{g}$ were used in the present study. The rats were obtained from the animal house of the National Research Centre, Egypt. The rats were kept individually in stainless steel cages at room temperature of about $25 \pm 2^{\circ} \mathrm{C}$, food and water were supplied ad-libitum.

\section{Diets}

A balanced diet was fed to rats all over the experiment. The diet composed of $11.9 \%$ casein (10\% protein), $10 \%$ corn oil, $45.73 \%$ maize starch, $22.87 \%$ sucrose, $5 \%$ cellulose, $3.5 \%$ salt mixture and $1 \%$ vitamin mixture.

\section{Methods}

\section{Preparation of plant materials}

Fruits and leaves of Carica papaya and Vitis vinifera, as well as Origanum majorana herbs were all washed by tap water. Carica papaya fruits were peeled off and the outer layer was discarded, the pulp was cut into small slices, the seeds were separated. Both the seeds and pulp of Carica papaya and all the other studied plant parts were dried separately in an air-circulated oven at $40^{\circ} \mathrm{C}$ till complete dryness. All dried plant materials were reduced separately into powder form.

\section{Preparation of plant extracts}

A known weight of each of the dried plants parts under study was placed separately in a continuous extraction apparatus (Soxhlet) and subjected to successive extraction using petroleum ether $(\mathrm{PE})\left(40-60^{\circ} \mathrm{C}\right)$ then absolute methanol $(\mathrm{MeOH})$ except for Carica papaya seeds that were only extracted by PE. For each extract the solvent was completely removed by evaporation under reduced pressure using rotary evaporator. Yield of each extract was weighed. The extracts studied in the present research were methanol extract of Carica papaya leaves and fruits, Vitis vinifera leaves and fruits, Origanum majorana herb, and petroleum ether extract of Carica papaya seeds.

\section{Preparation of the plant extracts' doses}

All the extracts were emulsified in distilled water using gum acacia.

\section{Animal experiment}

The rats were divided into 8 groups each of 6 rats. One group served as control normal healthy and another group represented control with ALD. Six test groups were designed; rats of each group received a daily oral dose $(250 \mathrm{mg} / \mathrm{kg}$ rat body weight) of the different plant extracts namely methanol extract of Carica papaya leaves, Carica papaya fruits, grape leaves and fruits, Origanum majorana herb and petroleum ether extract of Carica papaya seeds, separately by stomach tube. The doses were given through the whole period of the experiment which lasted for five weeks. The rats of the test groups and ALD control group received daily intraperitoneal $\mathrm{Al}$ lactate dissolved in saline started from the $2^{\text {nd }}$ week as $7.5 \mathrm{mg} \mathrm{Al}$ (from $\mathrm{Al}$ lactate) $/ \mathrm{kg}$ rat body weight till the end of experiment to induce Alzheimer's like disease (modified from Tanino et al., 2000). Rats of the normal control healthy group received saline intraperitoneally starting from the $2^{\text {nd }}$ week of the experiment till the end of the experiment. This group and the control of ALD also received orally only the vehicle given to the test groups as daily oral dose. All rats were fed on the balanced diet all over the experiment. During the experimental period; food intake and body weight of rats were followed twice weekly. After elapsing of the experimental period (5 weeks), total food intake, body weight gain and food efficiency ratio (body weight gain/total food intake) were calculated. At the end of the experiment, rats were anesthetized and blood samples were withdrawn from eye vein orbital after an overnight fast. Blood samples were divided into two parts one mixed with trisodium citrate for determination of erythrocyte sedimentation rate (ESR) according to Westergren (1921). The second part of blood was mixed with heparin as anticoagulant, followed by centrifugation at $3000 \mathrm{rpm}$ for $15 \mathrm{~min}$ to separate plasma for 
determination of vitamin C (Jagota and Dani, 1982), vitamin E (Desai and Machlin, 1985), nitrite (Montogomery and Dymock, 1961), cholinesterase (ChE) activity (Den Blaauwen et al., 1983), tumor necrosis factor- alpha (TNF- $\alpha$ ) (Stepaniak et al., 1995), and malondialdehyde (MDA) according to Satoh (1978). Rats were dissected, skulls were opened with bone scissor and brains were received on ice, and used for determination of acetyl cholinesterase activity (AChE) according to Ellman et al. (1961) and MDA (Ohkawa et al., 1979). ESR, and TNF- $\alpha$ are considered as biomarkers of inflammation.

MDA is biomarker of lipid peroxidation and oxidative stress. plasma nitrite is considered as biomarker of both inflammation and oxidative stress. Vitamin $\mathrm{C}$ and $\mathrm{E}$ are reflection of antioxidant state. The animal experiment was carried out according to the Ethics Committee of the National Research Centre, Cairo, Egypt, and followed the recommendations of the National Institutes of Health Guide for Care and Use of Laboratory Animals (Publication No. 85-23, revised 1985).

\section{Statistical analysis}

Values were expressed as mean \pm SE. Data of the animal experiment were analyzed statistically using ANOVA followed by Duncan test, $\mathrm{P}<0.05$ was the criterion of significance.

\section{RESULTS}

The yields of both petroleum ether and methanol extracts were determined as $\mathrm{g}$ extract $/ 100 \mathrm{~g}$ dry plant part. The highest yield belonged to methanol extract of grape $(55 \mathrm{~g})$ while the lowest was that of methanol extract of Carica papaya fruits $(8 \mathrm{~g})$. Methanol extract of Carica papaya leaves (23 g), Origanum majorana herb $(21 \mathrm{~g})$ and grape leaves $(20 \mathrm{~g})$ and petroleum ether extract of Carica papaya seeds ( $20 \mathrm{~g}$ ) were approximately equal. The biochemical results of different experimental groups are shown in tables 1 and 2. Control rats with Alzheimer's like disease (ALD) showed significant high level of ESR and plasma MDA, nitrite and TNF- $\alpha$ compared to control healthy. Plasma cholinesterase activity showed significant increase in Al lactate treated rats compared to control healthy. Plasma vitamin $\mathrm{C}$ and vitamin $\mathrm{E}$ were significantly low compared to normal healthy control rat group. The same group of rats showed significant increase in brain AChE activity and MDA compared to control healthy rats. Administration of the different tested extracts produced significant reduction in brain MDA compared with that of ALD-control rats except in case of methanol extract of Carica leaves. Administration of petroleum ether extract of Carica seeds showed the highest significant reducing effect in brain MDA level which matched the control healthy followed by methanol extract of grape leaves, grape fruits, Carica fruits and Origanum majorana. Plasma MDA was reduced significantly when any of the tested extracts was given compared to ALD-control but the level was still significantly higher than the healthy control. Methanol extract of grape leaves showed the highest reducing effect while both methanol extract of Carica fruits and leaves showed the least and equal significant reducing effect of plasma MDA when compared to ALD control. Plasma nitrite (as a measure of nitric oxide) was significantly reduced on administration of any of the studied extracts compared to that of ALD control and reached to the normal level and even was reduced more than that of healthy control in the majority of the tested groups. Methanol extract of grape fruits showed the highest reducing effect while methanol extract of Carica fruits showed the least significant reducing effect. All the studied extracts produced significant increase in plasma vitamin C compared to ALD-control rats except the methanol extract of grape fruits. Administration of methanol extract of Carica fruits produced the highest significant increase in vitamin $\mathrm{C}$ level. Treatment with methanol extract of Origanum majorana produced the lowest significant increase in vitamin $\mathrm{C}$ level. Administration of any of the tested extracts produced significant elevation in vitamin $\mathrm{E}$ level when compared with ALD-control. Methanol extract of grape fruits, produced the highest significant elevation in vitamin E level. Administration of methanol extract of Origanum gave the least significant increase in vitamin E level. Plasma TNF- $\alpha$ of all tested groups showed significant reduction compared with ALD-control rats. Rats given methanol extract of Origanum showed the highest significant reduction in TNF- $\alpha$ level. The rats administered petroleum ether extract of Carica seeds, methanol extract of Carica fruits or methanol extract of grape fruits showed more or less equal significant reductive effect towards plasma TNF- $\alpha$. The group given methanol extract of grape leaves showed the least significant

Table 1: ESR and plasma parameters of different experimental groups (mean \pm SE).

\begin{tabular}{|c|c|c|c|c|c|c|c|}
\hline Parameters & $\operatorname{ESR}(\mathbf{m m} / \mathbf{h})$ & $\begin{array}{c}\text { Plasma MDA } \\
\text { nmol/ml }\end{array}$ & $\begin{array}{c}\text { Plasma nitrite } \\
\mu \mathrm{mol} / \mathrm{l}\end{array}$ & $\begin{array}{c}\text { Plasma vit } \\
\text { C mg/dl }\end{array}$ & $\begin{array}{c}\text { Plasma vit E } \\
\text { mg/dl }\end{array}$ & $\begin{array}{c}\text { Plasma TNF- } \\
\alpha(\mathrm{pg} / \mathrm{ml})\end{array}$ & $\begin{array}{c}\text { Plasma ChE } \\
\text { activity (U/L) }\end{array}$ \\
\hline Normal healthy control & $1.17^{\mathrm{a}} \pm 0.17$ & $2.39^{\mathrm{a}} \pm 0.2$ & $3.30^{\mathrm{a}} \pm 0.36$ & $1.64^{\mathrm{a}} \pm 0.18$ & $0.183^{\mathrm{a}} \pm 0.018$ & $9.20^{\mathrm{a}} \pm 0.4$ & $177.3^{\mathrm{a}} \pm 11.7$ \\
\hline ALD-control & $18.70^{\mathrm{b}} \pm 1.02$ & $9.20^{\mathrm{b}} \pm 0.56$ & $6.70^{\mathrm{b}} \pm 0.54$ & $1.19^{\mathrm{b}} \pm 0.019$ & $0.085^{\mathrm{b}} \pm 0.002$ & $27.60^{\mathrm{b}} \pm 0.56$ & $212.4^{\mathrm{b}} \pm 7.4$ \\
\hline MeOH Carica papya leaves & $4.50^{\mathrm{c}} \pm 0.85$ & $5.36^{\mathrm{c}} \pm 0.19$ & $1.50^{\mathrm{c}} \pm 0.19$ & $1.64^{\mathrm{a}} \pm 0.113$ & $0.135^{\mathrm{c}} \pm 0.003$ & $15.32^{\mathrm{c}} \pm 1.17$ & $164.2^{\mathrm{a}} \pm 12.2$ \\
\hline $\mathrm{MeOH}$ Vitis venifera leaves & $4.50^{\mathrm{c}} \pm 0.72$ & $3.93^{c} \pm 0.13$ & $1.54^{\mathrm{c}} \pm 0.108$ & $1.88^{\mathrm{a}} \pm 0.1$ & $0.129^{\mathrm{c}} \pm 0.004$ & $18.30^{\mathrm{c}} \pm 0.21$ & $120.0^{\mathrm{c}} \pm 16.4$ \\
\hline MeOH Origanum majorana herb & $4.00^{\mathrm{c}} \pm 0.68$ & $4.52^{\mathrm{c}} \pm 0.49$ & $1.39^{\mathrm{c}} \pm 0.06$ & $1.43^{\mathrm{a}} \pm 0.05$ & $0.114^{\mathrm{c}} \pm 0.002$ & $11.99^{\mathrm{d}} \pm 0.59$ & $129.1^{\mathrm{c}} \pm 8.8$ \\
\hline MeOH Carica papya fruits & $5.30^{\mathrm{c}} \pm 0.88$ & $5.30^{c} \pm 0.16$ & $4.00^{\mathrm{a}} \pm 0.27$ & $2.03^{\mathrm{a}} \pm 0.2$ & $0.170^{\mathrm{a}} \pm 0.026$ & $17.00^{\mathrm{c}} \pm 0.96$ & $178.6^{\mathrm{a}} \pm 9.1$ \\
\hline $\mathrm{MeOH}$ Vitis venifera fruits & $6.20^{c} \pm 0.65$ & $0.39^{c} \pm 4.12$ & $1.22^{\mathrm{c}} \pm 0.13$ & $1.40^{\mathrm{b}} \pm 0.11$ & $0.180^{\mathrm{a}} \pm 0.012$ & $17.48^{\mathrm{c}} \pm 1.28$ & $134.2^{\mathrm{c}} \pm 6.2$ \\
\hline PE Carica papya seeds & $9.00^{\mathrm{c}} \pm 2.65$ & $4.38^{\mathrm{c}} \pm 0.47$ & $1.71^{\mathrm{c}} \pm 0.17$ & $1.96^{\mathrm{a}} \pm 0.24$ & $0.120^{\mathrm{c}} \pm 0.003$ & $16.98^{\mathrm{c}} \pm 1.6$ & $142.2^{\mathrm{c}} \pm 13$ \\
\hline
\end{tabular}

In each column different letters mean significant difference at $\mathrm{P}<0.05$

$\mathrm{MeOH}$ : Methanol extract. PE: Petroleum ether extract. 
Table 2: Brain acetyl cholinesterase activity (AChE) and MDA of different experimental groups (mean $\pm \mathrm{SE})$.

\begin{tabular}{|c|c|c|c|}
\hline Groups & Parameters & Brain MDA (nmol/g) & Brain AChE † \\
\hline Normal healthy control & & $0.033^{\mathrm{a}} \pm 0.003$ & $5.60^{\mathrm{a}} \pm 0.6$ \\
\hline ALD-control & & $0.105^{\mathrm{b}} \pm 0.005$ & $11.50^{\mathrm{b}} \pm 0.47$ \\
\hline MeOH Carica papya leaves & & $0.089^{\mathrm{b}} \pm 0.014$ & $4.90^{\mathrm{a}} \pm 1.2$ \\
\hline $\mathrm{MeOH}$ Vitis venifera leaves & & $0.053^{\mathrm{c}} \pm 0.007$ & $10.10^{\mathrm{b}} \pm 0.7$ \\
\hline MeOH Origanum majorana & & $0.069^{c} \pm 0.006$ & $11.30^{\mathrm{b}} \pm 0.21$ \\
\hline $\mathrm{MeOH}$ Carica papya fruits & & $0.061^{\mathrm{c}} \pm 0.006$ & $6.90^{\mathrm{a}} \pm 0.81$ \\
\hline $\mathrm{MeOH}$ Vitis venifera fruits & & $0.055^{\mathrm{c}} \pm 0.004$ & $8.90^{c} \pm 0.47$ \\
\hline PE Carica papya seeds & & $0.041^{\mathrm{a}} \pm 0.004$ & $10.30^{\mathrm{b}} \pm 0.41$ \\
\hline
\end{tabular}

In each column different letters mean significant difference at $\mathrm{p}<0.05$.

$\dagger$ Rates in $\mu \mathrm{mol}$ substrate hydrolyzed per min per $\mathrm{g}$ of tissue.

$\mathrm{MeOH}$ : Methanol extract PE: Petroleum ether extract.

Table 3: Nutritional parameters of different experimental groups (mean \pm SE)

\begin{tabular}{|c|c|c|c|c|c|c|c|}
\hline Groups & Parameters & $\begin{array}{c}\text { Initial body } \\
\text { weight (g) }\end{array}$ & $\begin{array}{l}\text { Final body } \\
\text { weight (g) }\end{array}$ & $\begin{array}{l}\text { Body weight } \\
\text { gain }(\mathrm{g})\end{array}$ & $\begin{array}{l}\text { Total food } \\
\text { intake }(\mathrm{g})\end{array}$ & $\begin{array}{c}\text { Food intake } \\
\text { (g/day) }\end{array}$ & $\begin{array}{c}\text { Food efficiency } \\
\text { ratio }\end{array}$ \\
\hline Normal healthy control & & $195.8^{\mathrm{a}} \pm 1.94$ & $278.7^{\mathrm{a}} \pm 4.5$ & $82.8^{\mathrm{a}} \pm 3.8$ & $485.3^{\mathrm{a}} \pm 12.40$ & $17.3^{\mathrm{a}} \pm 0.49$ & $0.172^{\mathrm{a}} \pm 0.006$ \\
\hline ALD- control & & $196.2^{\mathrm{a}} \pm 4.42$ & $210.5^{\mathrm{b}} \pm 5.8$ & $14.3^{\mathrm{b}} \pm 2.5$ & $364.5^{\mathrm{b}} \pm 11.40$ & $13.0^{\mathrm{b}} \pm 0.37$ & $0.039^{\mathrm{b}} \pm 0.006$ \\
\hline $\mathrm{MeOH}$ Carica papaya leaves & & $196.2^{\mathrm{a}} \pm 5.65$ & $218.5^{\mathrm{b}} \pm 3.9$ & $22.3^{\mathrm{c}} \pm 2.2$ & $374.5^{\mathrm{b}} \pm 18.60$ & $13.4^{\mathrm{b}} \pm 0.66$ & $0.059^{c} \pm 0.005$ \\
\hline $\mathrm{MeOH}$ Carica papaya fruits & & $195.2^{\mathrm{a}} \pm 5.95$ & $218.3^{\mathrm{b}} \pm 7.0$ & $23.2^{\mathrm{b}} \pm 4.6$ & $377.7^{\mathrm{b}} \pm 8.96$ & $13.5^{\mathrm{b}} \pm 0.32$ & $0.061^{\mathrm{bc}} \pm 0.012$ \\
\hline $\mathrm{MeOH}$ Vitis venifera leaves & & $195.2^{\mathrm{a}} \pm 3.90$ & $217.3^{\mathrm{b}} \pm 6.0$ & $22.2^{\mathrm{b}} \pm 3.5$ & $386.8^{\mathrm{b}} \pm 17.00$ & $13.8^{\mathrm{b}} \pm 0.60$ & $0.057^{\mathrm{bc}} \pm 0.008$ \\
\hline $\mathrm{MeOH}$ Vitis venifera fruits & & $196.0^{\mathrm{a}} \pm 4.70$ & $214^{\mathrm{b}} \pm 4.0$ & $17.8^{\mathrm{b}} \pm 3.6$ & $432.5^{\mathrm{c}} \pm 14.60$ & $15.5^{\mathrm{c}} \pm 0.53$ & $0.041^{\mathrm{b}} \pm 0.007$ \\
\hline $\mathrm{MeOH}$ Origanum majorana & & $196.0^{\mathrm{a}} \pm 3.96$ & $212.8^{b} \pm 5.9$ & $16.8^{\mathrm{b}} \pm 3.2$ & $402.0^{\mathrm{b}} \pm 21.60$ & $14.3^{\mathrm{b}} \pm 0.80$ & $0.044^{\mathrm{b}} \pm 0.009$ \\
\hline PE Carica papaya seeds & & $196.0^{\mathrm{a}} \pm 1.77$ & $210.5^{\mathrm{b}} \pm 2.3$ & $14.5^{\mathrm{b}} \pm 0.8$ & $359.8^{\mathrm{b}} \pm 7.00$ & $12.9^{\mathrm{b}} \pm 0.24$ & $0.041^{\mathrm{b}} \pm 0.003$ \\
\hline
\end{tabular}

In each column different letters mean significant difference at $\mathrm{P}<0.05$.

$\mathrm{MeOH}$ : Methanol extract, PE: Petroleum ether extract.

reducing effect on plasma TNF- $\alpha$ level when compared to ALDcontrol. ESR showed significant reduction in all studied test groups compared to ALD-control rats but the values are still higher than the healthy control. Methanol extract of Origanum majorana showed the highest significant reduction in ESR while petroleum ether extract of Carica seeds showed the least significant reducing effect. Plasma cholinesterase activity was inhibited on administration of any of the tested extracts compared to that of ALD-control rats. Methanol extract of grape leaves gave the highest significant anti-cholinesterase activity, coming next methanol extract of Origanum, methanol extract of grape fruits and petroleum ether extract of Carica seeds, whereas both methanol extract of Carica leaves and fruits have the least significant reducing effect towards the enzyme activity. Acetylcholinesterase activity in brain showed general reduction in all tested groups compared with ALD-control which was significant only on administration of methanol extract of Carica leaves, Carica fruits and grape fruits. Administration of methanol extract of Carica leaves produced the highest significant anticholinesterase activity when compared to ALD-control, followed by methanol extract of Carica fruits and grapsse fruits. Table (3) represents the effect of different plant extracts under investigation on the nutritional status of rats. During the development of Alzheimer-like model in rats, there was significant decrease in body weight gain, food intake and food efficiency ratio in ALDcontrol when compared to normal healthy control rats. The tested plant extracts showed improvement in both body weight gain and food efficiency ratio which was only significant on administration of methanol extract of Carica leaves.

\section{DISCUSSION}

Exploring the link between Aluminum and biomarkers in $\mathrm{AD}$ and investigating natural agents with known therapeutic advantage could advance the development of remedy for delaying the onset and/or deterioration of AD. Here we studied the efficacy of specific plant food extracts in reversing Al lactate induced neurotoxic cascades reflected in biochemical changes in ALDmodel in rats. Aluminum has been shown to be present in brain tissue in sporadic AD patients which support its involvement as causative factor (Mirza et al., 2017). Different models of AD were established; from which Tanino et al. (2000) used $10 \mathrm{mg} \mathrm{Al}$ (from Al lactate)/kg rat body weight as a daily intraperitoneal dose for a period of 4 weeks. Rats could not tolerate this dose in the present study. Reduction of the dose to $7.5 \mathrm{mg} \mathrm{Al} / \mathrm{kg}$ rat body weight verified the induction of oxidative stress, inflammation and activation of acetyl cholinesterase enzyme in the current study. These changes resemble the reported changes in AD in human. Elevation of oxidative stress was reflected in the increased level of brain and plasma MDA along with the rise in plasma nitrite and the reduction of antioxidants; vitamins $\mathrm{E}$ and $\mathrm{C}$ in plasma of ALD rat model. The increased oxidative stress in the present study on administration of aluminum agreed with a previous study conducted by Olajide et al. (2017). In Olajide et al study evidences 
of proteolysis were reported in neuronal axons and dendrites due to high oxidative stress that correspond to apoptotic changes in prefrontal cortex and hippocampus. The high oxidative stress in both brain and peripheral tissue of AD patients and animal models results from overproduction of oxidants species and decrease of antioxidant capacity. $\mathrm{A} \beta$, present in Al-animal model of ALD as well as in $\mathrm{AD}$ patients, induces the production of hydrogen peroxide, lipid peroxide and superoxide in neurons that contribute in the formation of amyloid plaques and neurofibrillary tangles. Oxidative stress could promote $\mathrm{AD}$ by stimulating macroautophagy of $\mathrm{A} \beta$ that may further induce cell death by destabilizing lysosomal membranes (Swomley et al., 2014; Prema et al., 2016). Al induces apoptosis in hippocampus and cortex mainly by the down regulation of anti-apoptotic mediators and upregulation of pro-apoptotic factors (Chaudhary et al., 2014).

Inflammation has a great role in AD pathogenesis. A link has been suggested between $\mathrm{Al}$, inflammation and $\mathrm{AD}$. The increased levels of inflammatory biomarkers represented by ESR and plasma TNF- $\alpha$ and nitrite, in ALD-model, compared to normal healthy group in the present study could be due to the formation of $\mathrm{A} \beta$ in the brain that has the ability to promote inflammatory cytokines which participates in memory deficit. Controversy concerning the level of TNF- $\alpha$ in $\mathrm{AD}$ patients was observed in literature. TNF- $\alpha$ is one of the inflammatory biomarkers that variably increase in $\mathrm{AD}$ serum. High levels of soluble TNF in serum and nervous system of AD patients was reported by Mac Pherson et al. (2017). The same authors showed that administration of soluble TNF inhibitor decreased beta amyloid plaque load in mice brain. On the other hand mean serum level of TNF- $\alpha$ was significantly high in Alzeheimer's disease patients compared to normal subjects (Demirci et al. 2017). Delaby et al. (2015) demonstrated no changes in TNF- $\alpha$ level in serum or cerebrospinal fluid of Alzeheimer's patients. Such discrepancies argue that any role TNF plays in AD is not exactly known for progression of the disease and needs further studies.

The extensive loss of central cholinergic function in $\mathrm{AD}$ brain is linked to impaired nerve growth factor signaling. Brain choline and cholesterol which are the precursor of the synthesis of acetylcholine were reduced in $\mathrm{AD}$ with concomitant increase in the activity of acetylcholine esterase which lead to dementia (Karami et al., 2015). Treatment with Al salts lead to elevation of neuronal AChE expression in rats (Olajide et al., 2017). Al interferes with cholinergic transmission and signaling, thereby, acetylcholine (Ach) metabolism is affected by Al (Yellamma et al., 2010). The present results showed that both the activity of brain AChE and plasma ChE were significantly elevated in Alzheimer model in rats that had intimate relation to learning and memory deficits after Al exposure (Kawahara, 2016).

Results of plant food extracts evaluation in ALD rat model demonstrated that all tested extracts showed significant reduction in plasma MDA, plasma nitrite, plasma TNF- $\alpha$, plasma $\mathrm{ChE}$ and ESR with variable degrees. Brain MDA was significantly reduced on administration of any of the tested extracts except in case of Carica leaves methanol extract. Plasma vitamin C was significantly elevated on treatment with the different extracts except grape fruits methanol extract. Also, plasma vitamin E was significantly elevated on ingestion of the different extracts. Brain $\mathrm{AChE}$ activity was significantly reduced on administration of methanol extract of Carica leaves and fruits, in addition to methanol extract of grape fruits and was only non-significantly reduced in case of the other extracts. It is suggested that these extracts which succeeded to inhibit brain AChE activity were those that are able to pass through blood brain barrier. It can also be proposed that if the dose level of the extracts that failed to elicit inhibiting activity on brain AChE increased they might succeed to produce the effect.

It can be noticed that the sequence of potency of the antioxidant and the AChE inhibiting activity of the extracts in invitro test of previous study (Abdel Fatah et al. 2009) was not exactly similar to that of the in-vivo experiment in the present study; however both tests reflected the antioxidant and AChE inhibiting activity of all extracts. This difference may be attributed to the gastrointestinal tract effect that may reduce or potentiate the activities. The activities could also be affected in-vivo by blood brain barrier passage. Again the sequence of the anti-inflammatory activity of the tested extracts in the results of acute inflammation test in Abdel Fatah et al. (2009) study did not coincide with that of the results showed in the present ALD-model (chronic inflammation) but the anti-inflammatory activity was confirmed in both tests.

Phenolic contents of the studied extracts as determined previously (Abdel Fatah et al., 2009) may have the upper hand in producing both the anti-inflammatory and antioxidant activity; however other important bioactive constituents have been reported.

Methanol extract of grape pomace and skin possess a high antioxidant and anti-inflammatory activities that could be attributed to the presence of resveratrol, flavonoids, flavons and anthocyanins represented by malvidine, delphinidine and petunidine (Aloui et al., 2016) that able to reduce ROS and MDA thus can play a role in ameliorating progression of AD. Resveratrol, a polyphenolic compound, can cross the blood-brain barrier and exert its neuroprotective effect as a radical scavenger through increasing heme oxygenase 1 activity which used to degrade the pro-oxidant heme (iron-protoporphyrin IX). Resveratrol has protective role in AD through inhibiting betasecretase and beta-amyloid generation ( $\mathrm{Hu}$ et al., 2015).The polyphenols in grape skin was reported to have protective role in degenerative and inflammatory diseases as well as enhancing brain mitochondrial respiration leading to improvement of dementia in aged mice (Calabriso et al., 2016; Asseburg et al., 2016).

Previously, Carica papaya was shown to reduce oxidative stress and inflammation (Gogna et al., 2015; Dejoie et al., 2016) and thus it could reduce the risk of disease caused by free radical. The present results of Carica fruits methanol extract which showed its increasing effect on both levels of vitamins $\mathrm{E}$ and $\mathrm{C}$ agreed with the previous mentioned studies that Carica 
contains both vitamins (Chukwuka et al., 2013). Tocopherol and ascorbic acid are promising in AD nutritional therapy. With respect to healthy subjects, significantly lower levels of vitamin A, $\mathrm{E}$ and carotenoids were found in $\mathrm{AD}$ patients. Both vascular dementia and AD were variably associated with reduced serum or plasma levels of the antioxidants vitamins A, C, E and carotenoids even when controlled for nutritional status. The mechanism underlying vitamin $\mathrm{C}$ therapeutic advantage relates closely to its free radical scavenging activity, prevention of membrane lipid peroxidation, modulation of neuronal bioenergetics, inhibition of AChE and through its anti-proteolytic effect (Olajide et al., 2017).Vitamin E as component in Carica papya was shown to play an important role in reduction of inflammatory disorders (Tahan et al., 2011). Carica methanol extracts also contains carotenoids like beta carotene, lycopene and beta cryptoxanthin that could participate in their antioxidant activity. Ethanol and methanol extracts of different parts of Carica were shown to possess antioxidant activity that was ascribed to the presence of phenolic and flavonoids (Asghar et al., 2016). The presence of caffeic, cinnamic, chlorogenic, quinic, coumaric, vanillic, and protocatechuic acids, naringenin, hesperidin, rutin, and kaempferol, in papaya leaves could participate in ameliorating the biochemical changes in AD (Gogna et al., 2015). Barbagallo et al. (2015) reported beneficial health effect of fermented Carica papya in AD patients due to its high antioxidant effect (Barbagallo et al., 2015).

The antioxidant and anti-inflammatory effect of Origanum majorana extracts proved in the present study agreed with the work of Soliman et al. (2016). Carnosic acid, a highly labile diterpene phenol with a structure similar to rosmarinic acid in addition to its derivative carnosol, that are present in Origanum majorana, both have antioxidant and anti-inflammatory activities. Origanum majorana herb contains up to $3 \%$ volatile oil, flavonoid glycosides, tannins, steroids and triterpenoids (oleanolic acid and ursolic acid) that contribute in the antioxidant and antiiflammatory activity of the herb. Ursolic acid reduced $\mathrm{A} \beta$ induced oxidative injury and inhibited AChE in AD (Heo et al., 2002; Chung et al., 2001). Also Origanum majorana extracts were shown to contain rosmarinic acid, luteolin-7-O-glucoside, apigenin-7-O-glucoside and caffeic acid that possess high antioxidant activity (Hossain et al., 2012).

Slight improvement in nutritional parameters (food intake, body weight gain, and food efficiency ratio) of rats with ALD-model was produced after administration of the different extracts. Weight loss has commonly occurred in the later stages of AD together with physical frailty and exhaustion (Namuka et al., 2016) that could be ascribed to high oxidative stress and inflammation. Cova et al. (2016) reported that progression towards $\mathrm{AD}$ and dementia is expected when weight loss is observed in mild cognitive impairment. Malnutrition is associated with dementia severity and geriatric syndrome in AD patients (Yildiz et al., 2015). Various explanations have been proposed for weight loss such as atrophy of mesial temporal cortex, biological disturbance or feeding behavior. So prevention of weight loss in AD patient is a major issue. Tanino et al. (2000) demonstrated that a statistically significant reduction in both brain and body weights was observed in the Al-treated rats compared with the control group.

Conclusion:

All the tested functional food components (plant extracts) showed antioxidant, anti-inflammatory, and anticholinesterase activity with different degrees pointed to their protective role during $\mathrm{Al}$ exposure as well as slowing the progression and/or onset of AD. This effect may be mainly attributed to their phenolic contents and other reported bioactive constituents. It is recommended to extend the search of the efficient extracts to clinical study. It could also be beneficial to consume the studied promising plant foods in daily life as protective tools towards AD and Al toxicity.

\section{ACKNOWLEDGMENTS}

This work was completely financed by the National Research Centre, Cairo, Egypt.

Conflict of Interests: There are no conflicts of interest.

\section{REFERENCES}

Abdel Fatah MM, Al-Okbi SY, Ramadan Kh R, Mohamed DA, Mohammed SE. Potential beneficial effect of functional food components in Alzheimer' disease. Academia Arena, 2009; 1(2): 55-68.

Aloui F, Charradi K, Hichami A, Subramaniam S, Khan NA, Limam F, Aouani E. Grape seed and skin extract reduces pancreas lipotoxicity, oxidative stress and inflammation in high fat diet fed rats. Biomed Pharmacother, 2016; 84:2020-2028.

Asghar N, Naqvi SA, Hussain Z, Rasool N, Khan ZA, Shahzad SA, Sherazi TA, Janjua MR, Nagra SA, Zia-Ul-Haq M, Jaafar HZ. Compositional difference in antioxidant and antibacterial activity of all parts of the Carica papaya using different solvents. Chem Cent J , 2016; 10:5.

Asseburg H, Schäfer C, Müller M, Hagl S, Pohland M, Berressem D, Borchiellini M, Plank C, Eckert GP. Effects of Grape Skin Extract on Age-Related Mitochondrial Dysfunction, Memory and Life Span in C57BL/6J Mice. Neuromolecular Med, 2016; 18(3):378-95.

Barbagallo M, Marotta F, Dominguez LJ. Oxidative stress in patients with Alzheimer's disease: effect of extracts of fermented papaya powder. Mediators Inflamm. 2015; ID:624801, 6 pages. doi: 10.1155/2015/624801. Epub 2015 Apr 7.

Calabriso N, Massaro M, Scoditti E, Pellegrino M, Ingrosso I, Giovinazzo G, Carluccio MA. Red grape skin polyphenols blunt matrix metalloproteinase-2 and -9 activity and expression in cell models of vascular inflammation: Protective role in degenerative and inflammatory diseases. Molecules. 2016; 21(9): pii: E1147.

Chaudhary M, Joshi DK, Tripathi S, Kulshrestha S, Mahdi AA. Docosahexaenoic acid amelioratesaluminum induced biochemical and morphological alteration in rat cerebellum. Ann Neurosci. 2014; 21(1):5-9.

Chukwuka KS, Iwuagwu M, and Uka UN. Evaluation of nutritional components of Carica papaya $\mathrm{L}$. at different stages of ripening. IOSR Journal of Pharmacy and Biological Sciences, 2013; 6 (4): 13-16.

Chung YK, Heo HJ, Kim EK, Kim HK, Huh TL, Lim Y, Kim SK, Shin DH. Inhibitory effect of ursolic acid purified from Origanum majorana $\mathrm{L}$ on the acetylcholinesterase. Mol Cells. 2001; 11(2):137-43.

Delaby C, Gabelle A, Blum D, Schraen-Maschke S, Moulinier A , Boulanghien J, Séverac D , Buée L, Rème T, Lehmann S. Central nervous system and peripheral inflammatory processes in Alzheimer's disease: biomarker profiling approach. Frontier in Neurology, 2015; 6:181. 
Demirci S, Aynal A, Demirci K, Demirci S, Arıdoğan BC. The serum levels of resistin and its relationship with other proinflammatory cytokines in patients with Alzheimer's disease. Clin Psychopharmacol Neurosci. 2017; 15(1):59-63.

Dejoie S, Boulmane R, Derbré S, Henrion D, Binachon C, Richomme P. Anti-inflammatory activity of a Carica papaya leaf extract used to prevent occasional gingivitis. Planta Med. 2016; 81(S 01):S1S381.

Den Blaauwen DH, Poppe WA, Trischler W. Cholinesterase with butyrylthiocholine-iodide as substrate: references depending on age and sex with special reference to hormonal effects and pregnancy. J Clin Chem Biochem, 1983; 21(6): 381- 386.

Desai ID, Machlin LJ. 1985. Vitamin E. In: Augustin J, Klein BP, Becker D, Venugopal, PB, ed. Methods of vitamin assay, $4^{\text {th }}$ edition. New York: John Wiley\& sons 225 - 275.

Ellman GL, Courtney KD, Andres V, Featherstone RM. A new and rapid colorimetric determination of acetylcholinesterase activity. Biochem Pharmacol, 1961; 7: 88 - 95.

Gogna N, Hamid N, Dorai K. Metabolomic profiling of the phytomedicinal constituents of Carica papaya $\mathrm{L}$. leaves and seeds by $1 \mathrm{H}$ NMR spectroscopy and multivariate statistical analysis. J Pharm Biomed Anal. 2015; 10; 115:74-85.

Grundman M, Corey-Bloom J, Jernigan T, Archibald S, Thal LJ. Low body weight in Alzheimer's disease is associated with mesial temporal cortex atrophy. Neurol, 1996; 46: 1585 - 1591.

Heo HJ, Cho HY, Hong B, Kim HK, Heo TR, Kim EK, Kim SK, Kim CJ, Shin DH. Ursolic acid of Origanum majorana L. reduces Abeta-induced oxidative injury. Mol Cells. 2002; 13(1):5-11.

Hossain MB, Brunton NP, Patras A, Tiwari B, O'Donnell CP, Martin-Diana AB, Barry-Ryan C. Optimization of ultrasound assisted extraction of antioxidant compounds from marjoram (Origanum majorana L.) using response surface methodology. Ultrason Sonochem. 2012;19(3):582-90.

Hu J, Lin T, Gao Y, Xu J, Jiang C, Wang G, Bu G, Xu H, Chen $\mathrm{H}$, Zhang $\mathrm{YW}$. The resveratrol trimer miyabenol $\mathrm{C}$ inhibits $\beta$-secretase activity and $\beta$-amyloid generation. PLoS One. 2015 Jan 28;10(1):e0115973

Jagota SK, Dani HM. A new colori-metric technique for the estimation of vitamin C using folin phenol reagent. Anal Biochem, 1982; 127: $178-182$

Karami A, Eyjolfsdottir H, Vijayaraghavan S, Lind G, Almqvist P, Kadir A, Linderoth B, Andreasen N, Blennow K, Wall A, Westman E, Ferreira D, Kristoffersen Wiberg M, Wahlund LO, Seiger $\AA$, Nordberg A, Wahlberg L, Darreh-Shori T, Eriksdotter M. Changes in CSF cholinergic biomarkers in response to cell therapy with NGF in patients with Alzheimer's disease. Alzheimers Dement. 2015; 11(11):1316-28.

Law A, Gauthier S, Quirion R. Say NO to Alzheimer's disease: The putative links between nitric oxide and dementia of the Alzheimer's type. Brain Res Brain Res Rev, 2001; 35: 73-96.

MacPherson KP, Sompol P, Kannarkat GT, Chang J, Sniffen L, Wildner ME, Norris CM, Tansey MG. Peripheral administration of the soluble TNF inhibitor XPro1595 modifies brain immune cell profiles, decreases beta-amyloid plaque load, and rescues impaired long-term potentiation in 5xFAD mice. Neurobiol Dis. 2017; pii: S09699961(17)30039-6.

Maya S, Prakash T, Madhu KD, Goli D. Multifaceted effects of aluminium in neurodegenerative diseases: A review. Biomed Pharmacother, 2016; 83:746-754.

Mirza A, King A, Troakes C, Exley C. Aluminium in brain tissue in familial Alzheimer's disease. J Trace Elem Med Biol. 2017; 40:30-36

Montgomery HA, Dymock JF. The determination of nitrite in water. Analyst, 1961; 86: 414 - 416.

Namioka N, Hanyu H, Hirose D, Hatanaka H, Sato T, Shimizu S. Oxidative stress and inflammation are associated with physical frailty in patients with Alzheimer's disease. Geriatr Gerontol Int, 2016. doi: 10.1111/ggi.12804.
Ohkawa H, Ohishi, N, Yogi K. Assay for lipid peroxides in animal tissues by thiobarbituric acid reaction. Anal Biochem, 1979; 95: $351-358$.

Olajide OJ, Yawson EO, Gbadamosi IT, Arogundade TT, Lambe E, Obasi K, Lawal IT, Ibrahim A, Ogunrinola KY. Ascorbic acid ameliorates behavioural deficits and neuropathological alterations in rat model of Alzheimer's disease. Environ Toxicol Pharmacol. 2017; 50:200-211.

Prema A, Thenmozhi AJ, Manivasagam T, Essa MM, Akbar MD, Akbar M. Fenugreek Seed Powder Nullified Aluminium Chloride Induced Memory Loss, Biochemical Changes, $\mathrm{A} \beta$ Burden and Apoptosis via Regulating Akt/GSK3 $\beta$ Signaling Pathway. PLoS One. 2016; 11(11):e0165955.

Kawahara M. Link between aluminum neurotoxicity and neurodegenerative disorders. Nihon Rinsho. 2016; 74(7):1176-85.

Saez-Valero J, de Ceballos ML, Small DH, de Felipe C. Changes in molecular isoform distribution of acetylcholinesterase in rat cortex and cerebrospinal fluid after intracerebroventricular administration of amyloid $\beta$-peptide. Neuroscience Letters, 2002; 325, 199-202.

Satoh K. Serum lipid peroxide in cerebro-vascular disorders determined by a new colorimetric method. Clinica Chemica Acta, 1978; 20: $37-43$.

Soliman AM, Desouky S, Marzouk M, Sayed AA. Origanum majorana attenuates nephrotoxicity of cisplatin anticancer drug through ameliorating oxidative stress. Nutrients. 2016; 8(5). pii: E264.

Stepaniak JA, Gould KE, Sun D, Swanborg RH. A comparative study of experimental autoimmune encephalomyelitis in Lewis and DA rats. J. Immunol, 1995; 155(5): 2762 - 2769.

Swomley AM, Förster S, Keeney JT, Triplett J, Zhang Z, Sultana R, and D. Allan Butterfield DA. Abeta, oxidative stress in Alzheimer Disease: Evidence based on proteomics studies. Biochim Biophys Acta, 2014; 1842(8): 1248-1257.

Tahan G, Aytac E, Aytekin H, Gunduz F, Dogusoy G, Aydin S, Tahan V, Uzun H. Vitamin E has a dual effect of anti-inflammatory and antioxidant activities in acetic acid-induced ulcerative colitis in rats. Can J Surg., 2011; 54(5):333-8.

Tanino H, Shimohama S, Sasaki Y, Sumida Y, Fujimoto S. Increase in phospholipase $\mathrm{C}-\delta 1$ protein levels in aluminum-treated rat brains. Biochem Biophys Res Commun, 2000; 271: 620 - 625.

Teunissen CE, de Vente J, Steinbusch HW, de Bruijn C. Biochemical markers related to Alzheimer's dementia in serum and cerebrospinal. Neurobiol Aging, 2002; 23 (4): 485 - 508.

Wang P, Wang ZY. Metal ions influx is a double edged sword for the pathogenesis of Alzheimer's disease. Ageing Res Rev. 2016 Nov 6. pii: S1568-1637(16)30132-5.

Westergren A. Studies of the suspension stability of the blood in pulmonary tuberculosis. Acta Medica Scand, 1921; 54: 247.

Yao ZX, Drieu K, Szweda LI, Papapoulos V. Free radicals and lipid peroxidation do not mediate amyloid-induced meuronal cell death. Brain Res, 1999; 847: 203-210.

Yellamma K, Saraswathamma S, Nirmala Kumari B. Cholinergic system under Aluminium toxicity in rat brain. Toxicol Int, 2010, 17 (2): 106-112.

Yildiz D, Büyükkoyuncu Pekel N, Kiliç AK, Tolgay EN, Tufan F. Malnutrition is associated with dementia severity and geriatric syndromes in patients with Alzheimer disease.Turk J Med Sci, 2015; 45(5):1078-81.

\section{How to cite this article:}

Al-Okbi SY, Mohamed DA, Fatah MA, Abdel-Aal K, Mohammed SE. Evaluation of Plant Food Extracts in Experimental Model of Alzheimer's Like Disease Induced by Aluminum Lactate in Rats. J App Pharm Sci, 2017; 7 (07): 070-076. 